\title{
THE CITY WALLS OF FLORENCE, A METHOD TO MANAGE INFORMATIONS OF A COMPLEX SYSTEM.
}

\author{
J.G. Vitale ${ }^{1, *}$ \\ ${ }^{1}$ University of Florence - jacopogiuseppe.vitale@ unifi.it \\ Commission II - WG II/8
}

KEY WORDS: City walls, Manage informations, Complex system, Heritage, Florence walls

\begin{abstract}
:
The city walls of Florence constitute a complex system: six circles and at least nine distinct phases of use and transformation, from the foundation of Florentia to Florence Capital, to contemporary adjustments. The DIDA, Department of Architecture of the University of Florence with the Municipality of Florence, has been carrying out since 2012 the FIMU project with the study of the various walls circuits and diachronic surveys of the surviving wall sections. The aim is to combine and harmonize the historical data with technical-scientific innovation, expressing its own vision of the relationship between the history of the city of Florence and the correct valorization of one of its important Landmark. Every citizen must be able to recognize in the traces of the past his belonging to a community, the results expected from this research are the realization of an informative-didactic and informative apparatus that will emphasize this important historical testimony of Florence and its transformations occurred over the centuries. Data acquisition, processing and visualization methods define this research as 'experimental' for the knowledge and evolution of a historic city that would contribute to elevating services for the technical scientific community and the citizen, to which data would become available currently 'raw' with the preparation of an apparatus based on a database through the 'Open Data' platform of the Municipality of Florence.
\end{abstract}

\section{INTRODUCTION}

1.1 Representation and communication of the urban landscape between tradition and innovation

The urban walls of Florence with its doors, its towers and its 'shortcomings' represent, for their historical importance and for their charm, one of the identity elements of the city. Despite this, however, they did not always get the deserved consideration.

The scarce usability of the tracks, from the Roman one to the medieval and Renaissance one, has worsened, both with the large urban renovations of the nineteenth century and with the more recent use of the areas adjacent to urban car parks, reducing the formal and visual continuity of the walls.

Responding to an appeal by the Municipality of Florence, since 2012 the Department of Architecture of the University of Florence (DIDA) and the Technical Services Office of the Municipality of Florence, carry out the study of the complex of the city walls, with surveys of the surviving wall sections and with direct and indirect specialist investigations. In 2016, the 'basic strategic research project' entitled "FI-MU - The city walls and the defensive system of Florence: representation and communication of the urban landscape between tradition and innovation" was approved and financed by the University of Florence.

The interdisciplinary project, with the creation of didactictraditional and didactic-IT supports, aims to bring the complex of urban walls to the knowledge of a wider public and to create specific visit routes through an articulated valorisation system. A correct enhancement policy, however, has the obligation to set up control and management systems to maintain the safety levels of the structures and visitors.
For this purpose, the 'Technological Infrastructure Development Service of the Information Systems Department' of the Municipality of Florence has made available its skills and the Geonetwork-OpenData platform of the Municipality of Florence, for the creation of a specific integrable archive, so as to allow various possibility of interfacing and the development of a management and maintenance plan for the structures and areas pertaining to them.

The studies and surveys carried out so far have allowed the acquisition of a large amount of documentary material of various kinds: from the characterization of the materials present to the identification of the alterations in progress, from a preliminary analysis of the building stratigraphy's to the updating of the visualization of the road systems and unsaturated neighbouring areas. A more efficient storage of data, with the possibility of their use for the definition of a 'Maintenance and management plan' of the complex of city walls with a high ratio between the investment for knowledge (costs) and the possibility of its use (benefits) supported by a Geographic Information System (geographic information system or even territorial information system), GIS an integrated data management tool, to which the Municipality of Florence and DIDA-UNIFI collaborated jointly in the role of a group of research composed by Prof. Arch. Roberto Sabelli, Prof. Arch. Fabio lucchesi, Prof. Francesco Salvestrini, Prof. Geol. Carlo Alberto Garzonio, Prof. Guido Vannini, Prof. Arch. Fabio lucchesi, Prof. Arch. Paola Puma, Prof Arch. Giacomo Tempesta, Arch. Carmela Pinto and the undersigned Arch. Jacopo G. Vitale.

\footnotetext{
* Corresponding author
} 


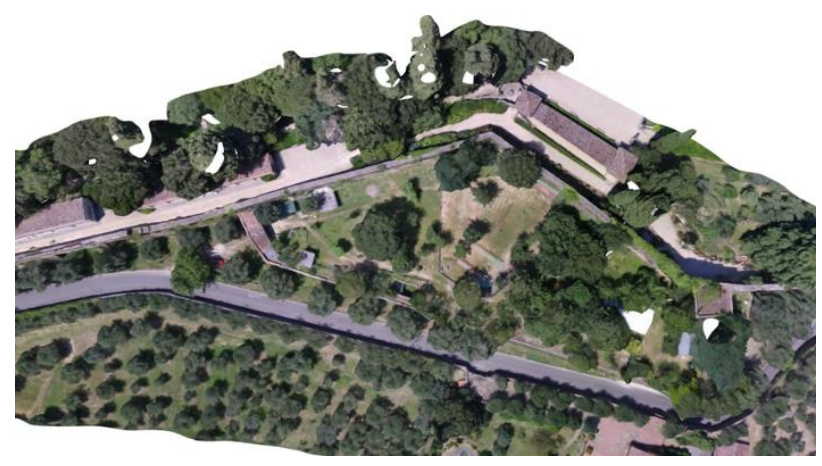

Figure 1. 3D surviving of the FI-MU project.

\subsection{Purpose of the project}

Since 2012, the Department of Architecture of the University of Florence (DIDA) with the Municipality of Florence has been carrying out the study of the complex of the city walls with a study of the surviving wall sections and with direct and indirect specialist investigations.

Thanks to the interest of the public administration combined with the passion of the DIDA, in 2016 a strategic basic research project was approved and financed by the University of Florence with the name of: "FI-MU The city walls and the defensive system of Florence: representation and communication of the urban landscape between tradition and innovation ".

The FI-MU project was approved with a selection procedure, through the judgment of three anonymous evaluators of the strategic basic research named: "History and society. Spaces, men, cultures between Antiquity and Modernity. Archaeological, historical, cultural profiles "[Call - D.R. 1374 (prot. 141735) of 27 October 2015 published on the Official Register of the University of Florence (n. 6923)].

The selection of the project was made according to the following criteria:

- Scientific quality of the proposed research and its methodology.

- Qualification of the scientific manager and participants in connection to the activities of the last five years and congruence with the sector covered by the proposal.

- Congruity between the funding requested and the objectives set.

- Coherence of the proposal with the indicated strategic line.

The aim of the project is to create an integrated information model for the complex of the Florentine urban walls, a helpful instrument for a moltitude of users, such as people connected to the world of education or to the Municipal Administration. In any case it is a useful data project to help the technician to plan all the necessary maintenance interventions.

The project combines and harmonize historical data with technical-scientific innovation, expressing its own vision of the relationship between the history of the city of Florence and the correct enhancement of its important landmark. The main purpose is to fill a deficiency in the dissemination of knowledge and enhancement of an architectural identity complex of the city, focusing on the reconstruction of the history collecting many types of data through the study of settlement strategies, the results the geometrical survey and representation of the urban landscape.
All the collected data are related to conservation with the most innovative communication techniques.

The project demonstrate that sustainable development can add value to a rich and extremely fragile territory. According to the Municipality, another purpose of the project is to promote the city wall system not only to attract and improve the tourism but also to inform the population of Florence about a landmark that today it's not possible to see and touch anymore.

The team elaborates a plan with multiples phases of organization and management of cognitive data to supply, according to a precise and controlled hierarchy of access and use of data, to multiple purposes: research, programming of maintenance and restoration, dissemination and enhancement of the entire wall system (city wall sections, city doors, towers and connected urban spaces).

Thanks to the Geonetwork - OpenData platform of the Municipality of Florence (directly connected with the DIDA and SAGAS platforms of the University of Florence), with 'Open Access' and / or 'Mandatory Access Control' levels, according to the different authorizations of access to data. For the realization of the necessarily interdisciplinary project, the team is composed by architects, archaeologists, a geologist (for the analysis of materials) and two experts of web GIS and data storage and management on the platform of the Municipality of Florence.

The main phases of the project are listed below:

- Selection and processing of the historical-descriptive documentation of the evolution of the buildings in relation to urban development.

- Elaboration of an archaeological stratigraphic reading integrated in the system of critical documentation of the project, obtained through a specific program of analysis of the walls and of 'light' readings of the urban context of reference.

- Writing of an archives of information about the walls and construction of the geometric 'geodata-base', thanks to updated and accessible web services, the team linked the existing and newly established archives to a complete georeferenced cartographic base of the urban walls; known coordinate points (from the "Geographic database of public spaces" of the Municipality of Florence, celerimetric survey of the territory on a scale of 1: 500, framed in the UTM-WGS84 Reference System) will constitute the cornerstones to which the map of the walls should refer, geographical basis to which all the information and iconographic materials of the existing archives will be reported; the development of a maintenance plan for the structures;

- Publication of research results applied to the advanced visualization of the studied urban complex, combined with traditional dissemination tools with particular attention to the description of the construction phases of the wall circuit, which characterize the evolution and transformations over the centuries.

- Proposal of itineraries to visit the city, a fundamental instrument for the sustainable development for the Florentine tourism. This is a proposal extended to the territory, the layout of the walls represents not a limit, inside / outside the historic city, but an element of connection between the congested historic centre and alternative tourist-cultural and landscape routes. 


\subsection{General historical-geographical framework}

For the Christian civilization, in Jewish and Roman tradition, the city constitutes a sacred and privileged space. The walls are a symbol of civilization, security, and distinction. The turreted crown went from Roman antiquity to the present day to signify the city reality, both as an urban and architectural fact (urbs) and as a human social, institutional reality (civitas). The figures of the circle and the square merging together shows the two main aspects of God: the perfect unity and the power of the divine manifestation. The fusion of them is as symbol of the perfect reality of the Incarnation, the God - Man who is circularly perfect and quadrangularly secure.

The most characteristic of these symbolic fusion figures is the octagon, a polygon that multiplies its sides to become a circle and a circle in which it inserts its circumference in the perimeter.

The octagon is the symbolic figure of the Christian Imaginary and widely represented in Florence by the Baptistery of San Giovanni. The tendency to represent the city through the image of the walls only, an 'empty circle', an idea that will last for a long time also in the Middle Ages to mark the qualifying diversity between urban fact and surrounding territory, but also their relationship, dialectics and interchange.

The Roman colony of Florentia (The latin name of Florence) was born around $59 \mathrm{BC}$. and was in the centuriation grid of the north side above of the Arno, coordinated on the axis of the Via Cassia.

According to the Roman urban-sacred tradition, Florentia was born as a quadrangular Castrum oriented following the four cardinal points. The quadrangular wall marked by the Pomerium is cut crosswise by the two basic lines, the Cardo in the north-south direction which hinges the city on the polar axis, and the Decumanus in the east-west direction, which follows the course of the sun.

The road cross, today, has its meeting point between via degli Speziale and via Roma, where the Forum once stood.

The archaeological discoveries suggest that the urban perimeter had a length of about 1800 meters, with an average width of 450 meters for each of the four sides of the brick curtain wall, interspersed with cylindrical towers, that surrounded the urban city centre.

In correspondence with the four outlets of the two road axes, there were as many doors flanked by cylindrical and truncated conical towers. The north gate was located along the current via Roma (Cassia) at the intersection with via De' Cerretani; the wall layout, oriented east-west, changed course at an angle of 90 degrees towards the middle of via de 'Banchi and ran parallel to the eastern side of via de' Tornabuoni, where the Mugnone served as a moat. The western gate was located there at the crossroads between the current via de 'Tornabuoni and via Strozzi. To the north of the Santa Trinita bridge the walls went east, up to the southwest side of Piazza San Firenze; the Decumana door then opened at the entrance of via Vacchereccia. The east section followed approximately the western side of Via del Proconsolo and the related door opened at via del Corso.

From the end of the 1st century A.D. there were, besides the Pomerium, villages inhabited by foreigners. Prosperity marks Florentia until the end of the 4th century. A.D. The decline begins with the fifth century. with the siege postulated by the Gothic Radagaiso. The situation worsened in the sixth century. with the Greek-Gothic war. The colony is significantly reduced, it is the phenomenon of Retractio, which causes the urbs to recede, changing it to Castrum. Subsequently there was the decline of the
Cassia, which was moved to the Valdelsa, leaving Florencia decentralized.

From the 9th century there is a new expansion of the city, 20002500 inhabitants, which recovers the size of the Roman city and expands considerably to the south, towards the banks of the Arno.

\subsection{The new city Circle}

The third city circle designed in 1284 with the advice of Arnolfo di Cambio and completed in 1333 is symmetrical to the second. The fifth and sixth circles were linked to the ancient orientation of the Roman centuriation. The two-fourteenth century circle remained sufficient to contain the whole of Florence; in fact, shortly afterwards epidemics and consequent demographic decline of the population, gave way to large green spaces that led to the creation of beautiful Renaissance gardens. Spatial planning saw the opening of new roads, such as via Larga, the gutting of many winding and narrow lanes and the affirmation of the new concept of wide and straight road, the construction of the lungarni, the regulation of the measures of roads, squares, buildings public and private. "Arnolfo builds a city with respect to the pre-existing building magma" (Fanelli).

In 1291 the municipality intervened harshly against illegal construction, imposing royalties on illegal construction workers and citizens interested in purchasing portions of old walls of which they had illegitimately appropriated. Sales of the old walls went from 1295 onwards so that the demolition of the old wall went hand in hand with the erection of the new one. Starting from 1298 anyone who made a testament was obliged to leave a contribution to the construction of the walls and the new circle, whose perimeter had been replaced after their demolition by that of the ring road, proceeded slowly and irregularly: economic reasons, politicians and military advised the recovery from time to time or forced its arrest. The government of Florence built doors like Porta alla Croce, San Gallo, al Prato. They were connected to each other with temporary defenses and then the curtain wall between the door and the door was raised. A decree of 1324 provided that to reinforce this curtain there must be ditches and bastions in addition to the towers, while a document from 1323 prohibited the construction of buildings that approached the new walls more than four meters. From 1284 to 1298 the works were stopped, and the foundation stone of the new wall was placed in front of Porta al Prato in November 1299.

\subsection{The Oltrarno}

The first settlements was born along the route of the Via Cassia Nova and at the intersection with the roads that came from Pisa and Volterra. During the Hadrian age a large settlement arose thanks to the Syrian pilgrims, as well as those who introduced Christianity to Florentia. Around the fourth century there must have been a protoChristian cemetery area around the place that would later be occupied by Santa Felicita. With the foundation of the church of San Miniato, in 1018, the Oltrarno became an increasingly sacred area in Florence. From the caput Pontis three road routes began to radiate: once to the east, towards the plain of Ripoli; one left the river perpendicularly towards Siena; the third proceeded parallel to the river, to the west. Since the thirteenth century more news has come thanks to a group of notaries who worked there. Between 1218 and 1220 was built the Ponte alla Carraia, the New bridge, placed in such a way as to place the Oltrarno in direct communication with the west corner of the Cisarnina wall of 1172 . Symmetrically in 1237 the bridge to the Graces was built (Rubaconte) which connected the area with the southeast corner of the Cisarnina wall. These two bridges can be considered as a sort 
of Trait d'union belonging to the wall fence. The bridge to Santa Trinita was the last in 1252 which was to connect the old center to the village of San Felice. In fact, it was in the years of the Government of the Primo Popolo, between 1250 and 1260, that the urbanization of the Oltrarno took off definitively, with a series of initiatives such as the organization of the new via Maggio, which connected the Santa Trinita bridge to the church of San Felice through the Casellino area, the extension of via de'Serragli beyond the corner of via Sant'Agostino where the road met the walls.

\subsection{Instrumentation used}

Thanks to the funds allocated by the University of Florence, it was possible to purchase the necessary equipment to carry out the instrumental survey activities on site and obtain a fluid data management for a complete restitution of the geometry and the conservation of the existing portions of Florentine walls.

The instruments used are listed below:

- Faro Focus M70 laser scanner capable of performing measurements with a radius of $70 \mathrm{mt}$ per scan with precision up to $\pm 3 \mathrm{~mm}$. This kind of laser scanner is capable of acquiring $360^{\circ}$ images for each individual scan and superimposing them in photomosaic up to 165 megapixels.

- Data processor composed of AMD Ryzen 7 1800X 8-core 3.60 Ghz processor, $64 \mathrm{~GB}$ of ram memory, nvidia GTX 1080x 8GB graphics card.

- Leica FlexLine TS02 total station with precision of $1.5 \mathrm{~mm}$ for each registered point, generously made available by DiaCon srl, Spinn-Off of the University of Florence.

- DJI Phanthom 4 drone with 20 MP CMOS 1 sensor, generously made available by Prof. Lorenzo Rossi of the Department of Earth Sciences.

- Autodesk ReCap software for managing and merging the information from the laser scanner.

- Autocad 2018 software for managing information from the total station.

- Agisoft Photoscan software to obtain georeferenced high resolution orthophotos and DEM (Digital Elevation Model) accurately detailed.

It is a highly respected data processing system that guarantees excellent fluidity of information flows.

The critical aspect of this type of data acquisition is a fluid workflow to manage the job: the large amount of information inexorably causes problems of physical hard disk spaces and a complex hardware resources for a good processing.

\section{OPERATIONAL PHASE}

\subsection{Main geometrical surveys}

From Porta Romana from Viale Francesco Petrarca to the Piazzale di Porta Romana and Piazza della Calza;

- Boboli Gardens stretch of surviving walls inside the park that runs along Viale dei Cipressi up to the Bobolino district including part of the Porcelain Museum and the private houses below;

- Via di Belvedere from Porta San Giorgio to Porta San Miniato, including the Bulwark of Geneva and part of the Bardini garden, including part of Via Costa San Giorgio;

- Torre della Zecca including its interior, Piazza Piave and part of Via Giovane Italia;

- Porta Beccaria including all Piazza Cesare Beccaria, a small part of Via Giovane Italia and Viale Giovanni Amendola.

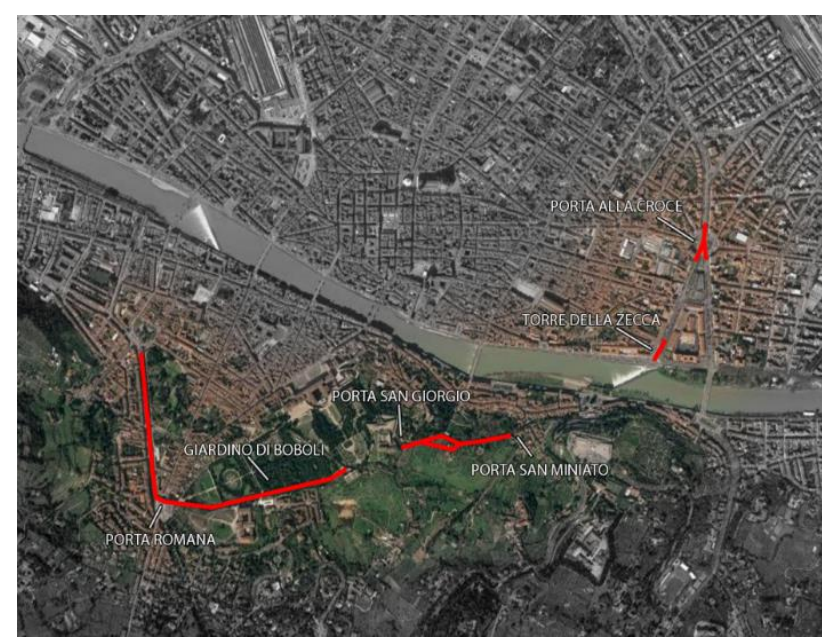

Figure 2. Framing surviving wall sections affected by the FIMU project.

\subsection{In-Place Surveys, Geometric Data Acquisition}

First of all, we evaluated the type of instrument and the relevant parameters for the survey, setting the levels of resolution, precision and accuracy, dictated by a critical analysis of the size, geometry, position and material of the portion of the section of wall to be measured. After that we planned the survey by choosing the right positions. All these preliminary evaluations have the double advantage of optimizing the process and at the same time foreseeing the possible problems connected to it.

Considering as an example the portion of a wall, the instrument must be positioned in specific position named 'Station' close to the object of study to collects the radiance data of the various scanned points and the available colour information.

The various stations where the laser scanner is positioned must be in sight of each other up to a maximum distance of 10 meters from each other, in this way it is possible to automatically join all the point clouds collected. To do that it is necessary to collect as many points in common as possible between one scan and another, drawing with the stations a linear and closed path.

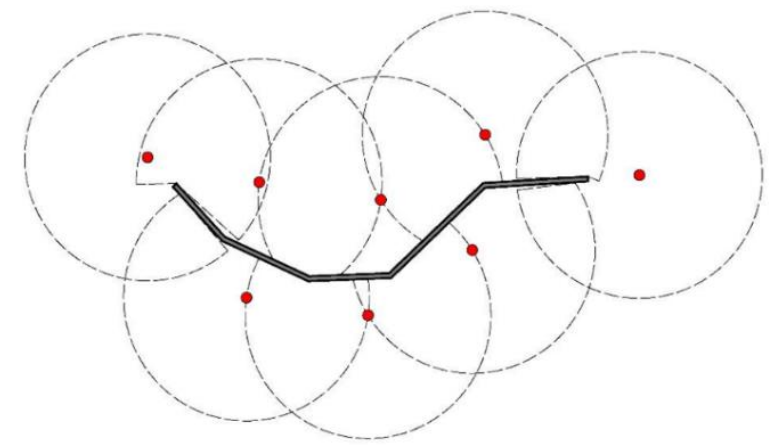

Figure 3. Example of survey planning with Laser Scanner, in red the stations, the dotted circles the scanning area and in the middle of the wall section object of the relief.

The difficulties of this type of survey are related to the laser radiation of the instrument, in fact it does not exceed opaque objects, is reflected by glossy objects and passes through transparent surfaces, this can distort the data, obstacles create shaded areas in to which the scan will take no point, the reflective surfaces return a false information on the affected object while the transparent ones are crossed by collecting points that would otherwise be hidden. 
Thanks to the Laser Scanner it is possible to complete a scanning station in 7 minutes only and the data collected is saved on the scanner's memory together with the photos taken by the integrated camera and the information of the radiance.

The use of the total station was essential to record known points in common with the data management system of the Tuscan region in order to be able to overlap our geometric data with the coordinate system of the 'Geoscope' platform of the Regione toscana.

\subsection{Data restitution}

Thanks to the laser scanner we can obtain the skin, a series of points that characterize the artifact detected. Obviously, it is not possible to obtain information about the building stratigraphy or areas outside the range of the instrument.

It is therefore a series of 'raw' data to be processed in a phase after the acquisition thanks to dedicated software.

After collecting the results of the scans, the various point clouds obtained are combined into a single overall cloud of the entire object that we want to detect, trying to align the various stations as much as possible to minimize any alignment errors in the measurements.

This operation is partly automatic, but in most cases the alignment must be done manually with identification of common points.

When the main point cloud is ready it is necessary to check its size in GB and manageability, to understand if it is possible to eliminate unnecessary parts such as the foliage or even decide to decimate the points recorded to make subsequent modeling work easier with a dedicated software.

After that we proceded with the 'meshing' phase of the cloud, the dedicated Autodesk Recap program can automatically create surfaces made up of triangles whose vertices are the points of the cloud and the sides are the segments that connect them, in this way it is possible to create a surface that describes as much as possible the shape of the elements that have been detected, the resolution of the surface improves if the point cloud contains a lots of point but at the same time it is necessary a great computer power to manage it.

The goal is not to obtain a surface with a high detail definition for a realistic photo rendering, but it is useful to obtain an object that can be inserted in a point cloud modeling and management software such as Autodesk Autocad that can retain all its geometric characteristics, without losing anything both in quality and precision.

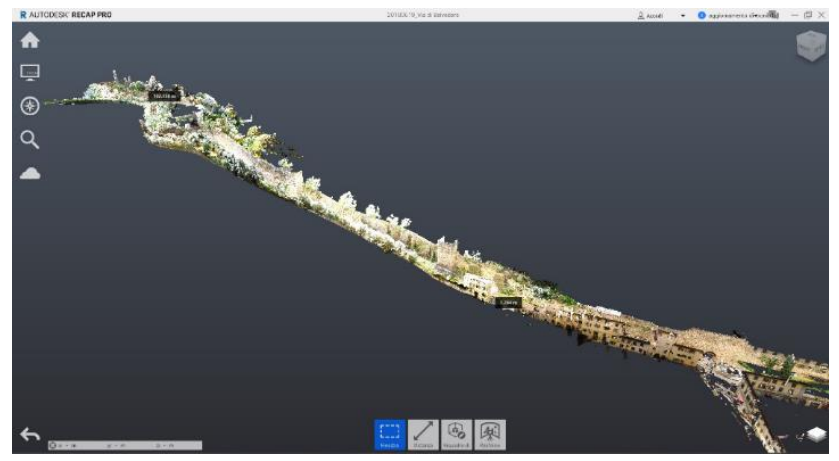

Figure 4. From Porta San Giorgio to Porta San Miniato.

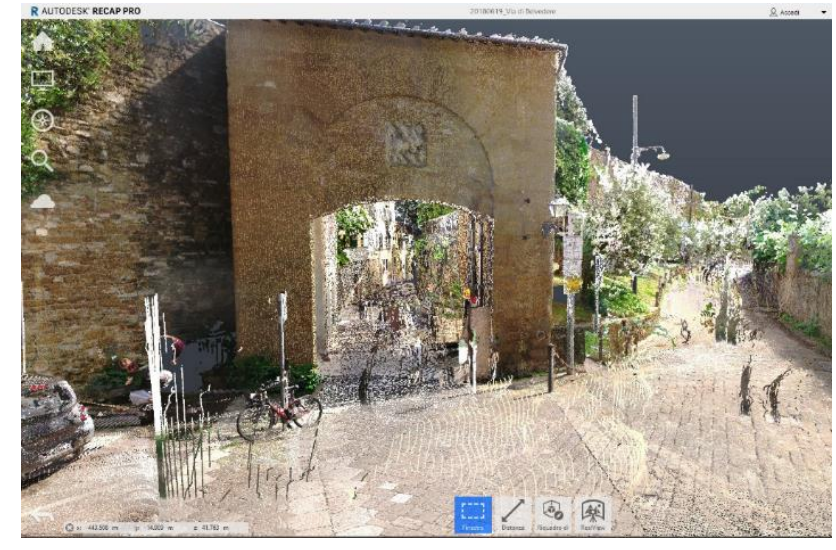

Figure 5. Detail of di Porta San Giorgio.

\subsection{Data processing}

For simplicity I'm reporting only one of the wall portions examined by the project, to warn all the others as it contains the problems that are common, in general, to the whole wall circuit in question.

This is a portion of the survived walls located Oltrarno in the San Niccolò district on the slopes of the San Miniato hill. It starts just before Porta di San Miniato at the beginning of Via di Belvedere and continues along the street until reaching the first defensive tower, for a total length of about $110 \mathrm{mt}$.

It is an ancient and very important part of the city, also mentioned as the "Scalea del Monte alle Croci" by Dante Alighieri in the "Divine Comedy" (Purgatory, XII, 100-102) and it is located in the proximity of the church of San Miniato al Monte.

The entire defensive line in the San Niccolò district is part of the Second Municipal Circle of Florence, dated 1.258-1.333, designed by the architect Arnolfo di Cambio. Over time these walls have undergone various processes of transformation, such as the substantial modification of the walls in the 16th century, since the introduction of firearms led to the scaling down of the walls, disadvantaging the towers and removing the most fragile elements from the walls, such as the ridges.

There are also many iconographic representations that were made between the fifteenth and sixteenth centuries, which represent the city within its walls in a very extensive landscape context, such as the famous 'Plan of the Chain', dated 1.471-1.482 and painted by Francesco di Lorenzo Rosselli, a bird's-eye view of Florence, or the Plan by Stefano Buonsignori, an axonometric view of the entire municipal area created in 1.584 and with 'updates' of 1.594 , which shows us the evolution of the city and its walls over time.

The entire section was analysed by a laser scanner and a total station to create the preliminary planimetric network to define a single reference system for the entire survey and cadastral framework.

The network was built as an autonomous structure, intrinsically determined, with superabundant measures to allow statistically valid controls.

All the documentation was a support to create an overlapping graphic, identifying the surfaces to be subjected to restoration. 


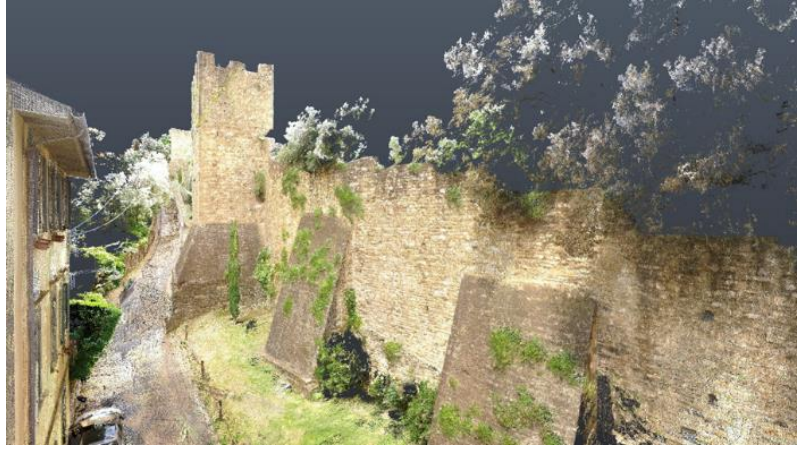

Figure 6. Point cloud detail of the section under examination

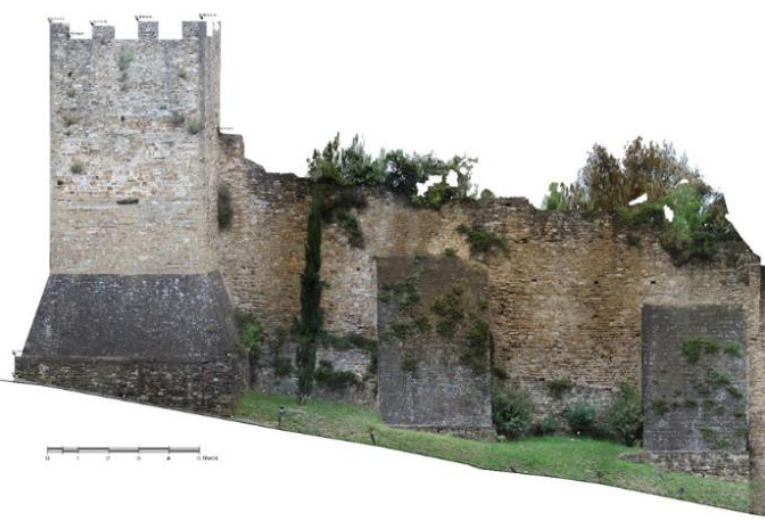

Figure 7. Wall elevation plan on Belvedere Street

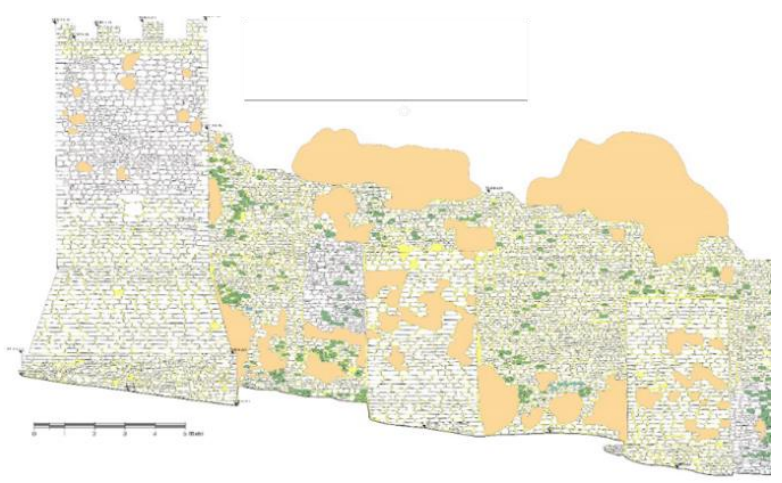

Figure 8. Wall elevation plan on Belvedere Street - Materials: In white the Pietra Forte, in Green the Pietra Alberese, in Yellow the lime mortar, in Light blue the Pietra serena, in Grey the cement mortar, in Orange the Vegetation.

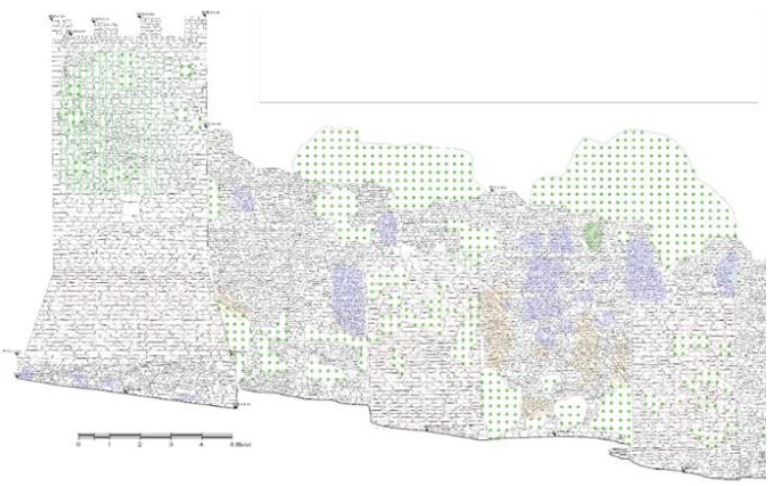

Figure 9. Wall elevation plan on Belvedere Street -

Deterioration: The green dots are the vegetation, in Orange the Erosion, in Violet the exfoliation, the Green lines are the organic patina.

\subsection{Observations on the state of conservation}

In a first analysis the walls showed a widespread erosion of the mortar joints and some ashlars, due to the exposure to atmospheric and polluting agents. The lower and upper parts show rooted weed vegetation, which causes cracks in the mortar joints and detachments of the material of the covering mantle.

The prospects are particularly humid with frequent stagnation of water, despite the southern exposure and has a widespread colour alteration of the materials and a widespread microbiological attack, with consequent formation of crusts and efflorescence. It should also be noted the presence of deficiencies on the wall facing. Cleaning is therefore necessary on the areas affected by the black crusts, the efflorescence, these are the cases where there is the biological patina. The presence of vegetation or the consolidation works made in the years, caused the erosion of the stone that make up the wall.

Obviously where there are shortcomings of stone it is necessary to intervene with additions of stone and non-stone material.

All the data of the wall section have been implemented in a GIS system for an easier use by the Administration of the Municipality of Florence and the Regione Toscana. In addition to the undersigned, the production of the files containing the analysis was also carried out by Prof. Roberto Sabelli and by the students of his Restoration I and II course. Polito Michela Eleonora and Trivigno Gabriele.

\section{GIS PROJECT MANAGER}

\subsection{Planning policy and tools}

Regional urban planning laws, such as in Tuscany the regional law of 10 November 2014, n. 65 "Rules for the government of the territory", have significantly changed the traditional approach of the government of the territory by introducing, among others, the compulsory nature of drafting knowledge boards.

Subsequently, it regulated the procedures for drafting them. The aim of the standard written in the law are an instrument to be able to analyse spatial data of different types through uniform and standardized criteria and methodologies.

The instrument identified is the SIT Territorial Information System:

- Main reference for all information and planning documents of the territory.

- Makes constantly updated data available to all citizens.

- Allows you to consult the basic cartography to navigate on interactive maps.

- Allows access to legislation and information sheets.

- Allows you to download forms and official documents.

- Gathers the legislation and all information about the Territorial Planning.

The SIT is therefore a new tool for the management and analysis of geographic data, as well as a complex set of hardware components, software, human and intellectual resources to acquire, process, analyze, store and return graphically data referring to a territory.

It could also be interpreted as a tool to organize and updating over time a system of knowledge of the territory, resources and its use, as well as support for territorial planning through the coordinated management of shared data archives and the involvement of operators (Public administrations, citizens and technicians) in the planning and implementation of activities that affect the management and maintenance of goods at various scales. 
The Regione Toscana provides a tool called 'GEOscopio', an online database accessible by any type of user, it is a webgis in which it is possible to view and query the geographic data of the Regione Toscana from the WMS of the region itself. The WMS are consultation services that allow to perform at least the following operations: display, navigation, variation of the display scale (zoom in and zoom out), variation of the portion of the framed territory (pan), overlapping of the territorial data sets available for consultation and display of the information contained in the legends and any relevant metadata content (Directive 2007/2 / EC). Implemented according to the INSPIRE guidelines for the implementation of Consultation Services with ISO 19128 - Web Map Service (WMS) 1.3.0 standard.

The WMS (Web Map Service), generated according to the standard, provides a map which is the representation of spatial information in the form of a digital image file of various formats and superimposable.

The WMS made the datas available in the form of a searchable archive and are precisely called 'Services'. To do this project, the team drew on the data shared through GeoScopio_WMS which are partly owned by the Tuscany Region, partly produced by other public bodies, available as a copy or as a processing of the original data held by the various owner bodies.

Geoscopio is the name of a set of portals, created by the Regione Toscana using the Tolomeo framework (http://tolomeogis.comune.prato.it/), which present a series of thematic layers to provide geographic information in a coordinated manner. All the data displayed comes from the Inspire services of the Regional Geographic Infrastructure WMS Geoscope, dynamically requested by the portal. The portal interacts with the data assets (to request maps, query layers, perform searches) exclusively through invocations of Web services as required by the Inspire Directive: in this way it will be possible to progressively add information layers made available by the various public subjects through the query of special interoperable web services activated by these subjects, without the need for data duplication, but drawing in real time from those maintained by the relative manufacturer.

The same Web databases can also be used by GIS Desktop tools such as QGIS, the software used to process the data stored during the FI-MU project.

\subsection{Building of the model}

Thanks to the geometric data previously acquired, we were able to start the construction of a GIS model by interpolating them with the data from the various WMS services.

As a first idea we were predisposed to the use of the $2 \mathrm{~K}$ ctr data and therefore in a scale of 1:2000 but the approximations of the vectors that describe the skeleton of the system are too many approximated for the intended purpose. The set of CTR component data is obviously geo-referenced but in general it does not aim to act as a precise basis for operations that require an order of precision close to one centimetre, such as the tools used during the survey phases.

After various considerations, the team used as most reliable the orthophoto of the Military Geographical Institute (IGM) made available by the Regione Toscana through the Geoscope portal.

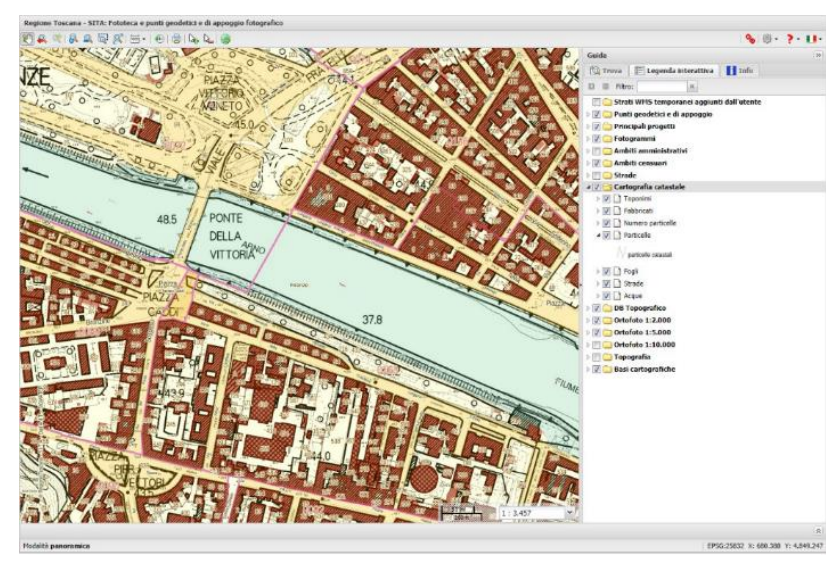

Figure 10. Geoscope layout.

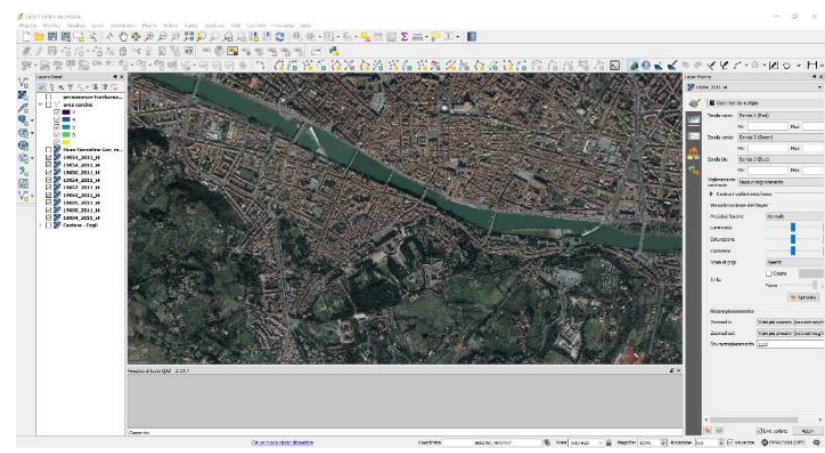

Figure 11. IGM map base layout.

To be sure of a good positioning, according to the reference points known as the large historic buildings or squares, the team decided to implement the historical maps made available by the CASTORE from 2013 to 2016. It provides the historical maps available to administrators, technicians, schools, and scholars of the territory thanks to the tools disseminated on the net, to enrich the regional cartographic heritage functional to the knowledge, use and management of the territory and the Tuscan landscape.

Each map was digitally reproduced in high resolution and enhanced as far as possible. The use of the cartographic data is contextual to large descriptive cards on the same documents.

Historical maps are, in fact, working tools widely used both in historical-geographical and territorial research, and in the technical practice of landscape and territorial planning. It is evident, in this sense, the fundamental role of support to the specific case in which, thanks to a primary source such as the cartography of the past, which can be easily compared with that of the present to highlight the historical permanence and the articulated mosaic cultural heritage with the transformations that have occurred over time in the current environmental and landscape frameworks. Although it has been digitized by raster scanning and therefore does not allow correct georeferencing.

With this project we have managed to offer an easy key to understanding the evolution of the Florentine building heritage and the relationship that the walls had with the city. 


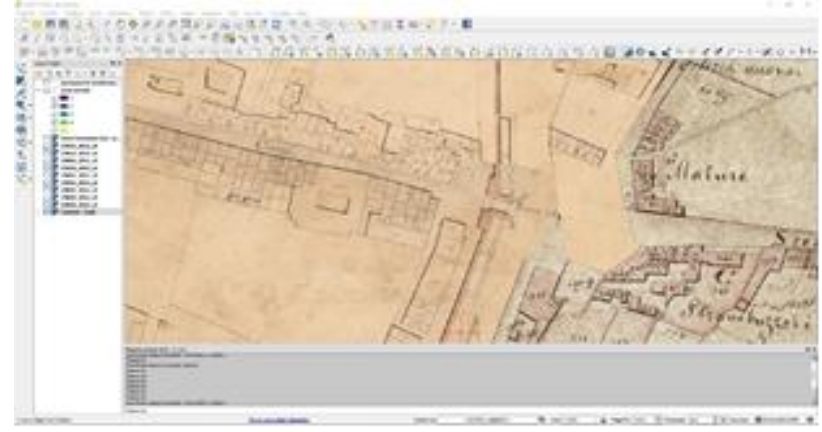

Figure 12. CASTORE map inside the GIS model.

Being the vast majority of non-geometric or geodetic representations, each map was implemented in the system with its own geolocation coordinates. There was no cross-checking with GPS data for various reasons. One of these is the fact that the CASTORE, in itself, has already been geolocated, through the recognition of main and secondary toponyms, with the geographical coordinates of the territorial 'footprint' of the cartographic representation, in order to obtain geographically ordered results.

Once the bases are ready, we begin to draw the portions of walls detected with the tools and software that we had available in vector and to transfer the data of the cards in the form of attributes into specific databases that are simple to organize but highly effective for the purpose of an environment of type GIS. The elements in a vector have the same type of geometry (e.g. they are all lines) and the same types of attributes (e.g. information on the specific composition of a masonry for a vector of walls).

It is an easy way to represent real world elements in a GIS with all the attributes that we believe are necessary at the prefixed level of detail. Thanks to the fact that a vector element can have a point, line or polygon type geometry, we are able to draw any type of geometry with the simple limitation of not being able to appreciate the elevation data ( $\mathrm{Z}$ axis) as in a 3D modeler.

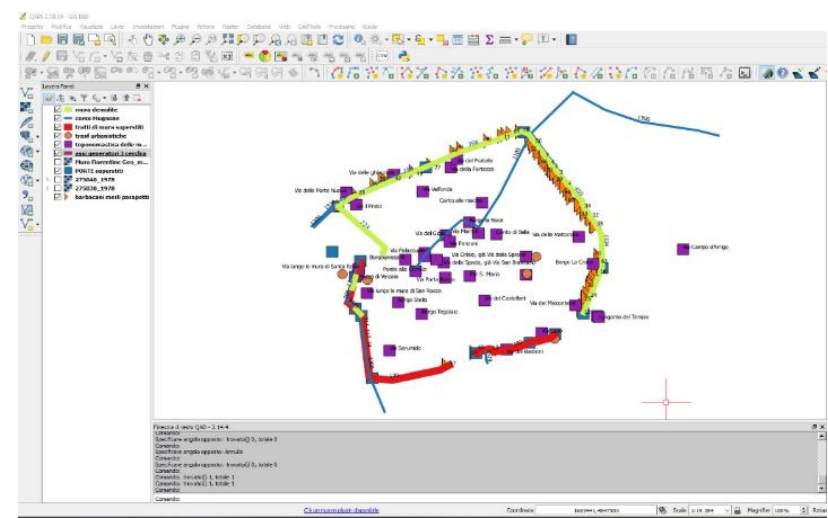

Figure 13. Geometrical filling of the attribute table.

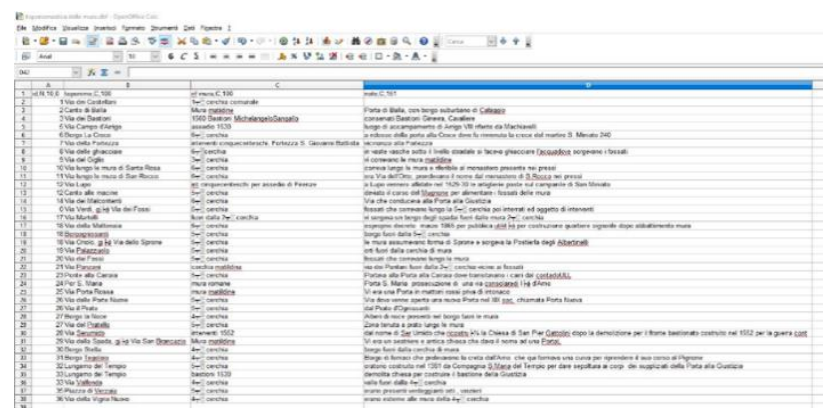

Figure 14. Textual filling of the attribute table.

\section{CONCLUSIONS}

The result obtained is therefore a questionable GIS data model in which any segment is represented by a geographical element (punctual, linear, polygonal) and is associated with a grid of attributes (collection of information) whose manipulation allows to extract maps and thematic analysis. Through the construction of a logical data model, the overlapping of information takes place not only on the visible plane of the map, but above all at the level of the grid of attributes / information that must be reported from one information level to another, associating different attributes with each other without having to alter the physical structure of the element itself.

The model obtained and all the data collected were delivered to the Regione toscana and to the Municipality of Florence to be implemented within the 'Open Data' system which can be consulted online at https://opendata.comune.fi.it /

At this moment, the data provided are under consideration by the municipal administration, which has proposed to coordinate, direct and promote knowledge of the cultural heritage by trying to communicate and transmit the heritage through the analysis of the public, current or potential, to which we turns. In this sense, they are focusing on carrying out surveys on the types of users to identify operating models and forms of communication aimed at the various audiences who frequent the places of 'Online' culture.

A priority element for the enhancement of this type of work is in fact to attract as many visitors as possible through the analysis of user needs and interests, in order to create an added value that allows to respond qualitatively and quantitatively to the expectations that visitors manifest in the relationship with this 'new' type of cultural popularization.

In fact, now, the task of the Administrations involved in the FI-MU project is to encourage the development of culture, proposing itself as an active subject in the process of creating services, in the ability to encourage the use of the heritage by technicians and all citizens, in the possibility of increasing cultural circuits and in proposing suitable tools to achieve satisfaction by the users of this service.

\section{REFERENCES}

Anichini, L., 2010. Alle porte coi sassi. Storia e guida alle porte delle mura di Firenze. Nicomp Laboratorio Editoriale. Firenze.

Consiglio Nazionale delle Ricerche, 2014. CNR-DT 212/2013, Istruzioni per la Valutazione Affidabilistica della Sicurezza Sismica di Edifici Esistenti, Roma. Online: www.cnr.it/documenti/norme/lstruzioniCNR_DT212_2013.pdf.

Coppola, M., 2018. Le indagini tipologiche in architettura, leggere il costruito con metodi non strumentali. Carocci editore. Roma.

Sabelli, R., 2017. The safeguarding of Mixed Sites: from recognition to enhancement. RESTAURO ARCHEOLOGICO, vol. Speciale 2017, pp. 182-198.

Simeone, D., Cursi, S., Tolda, I., Carrara, G., 2014. B(H)IM Built Heritage lnformation Modelling. Extending BIM to historical and archeological heritage representation. In Fusion, Proceedings of the 32nd lnternational Conference on Education and research in Computer Aided Architectural Design in Europe, eCAADe: Conferences 1. Newcastle upon Tyne, UK: Northurnbria Unìversity. Voi. 1.Pp. 613-622.

Pesaresi, C., 2017. Applicazioni GIS. Principi metodologici e linee di ricercar, UTET Università, Roma. 